\title{
Analysis of Transverse Flux Machines using a Virtual Mutual Inductance Approach
}

\author{
Jaime Renedo Anglada, Student Member, IEEE, and Suleiman M. Sharkh, Senior Member, IEEE
}

\begin{abstract}
In this paper a virtual mutual inductance approach is used to analyse the performance of transverse flux machines (TFMs). The virtual mutual inductance between the stator windings and the magnets' equivalent currents is obtained by integrating the flux produced by the stator windings over the surface of the magnets. Key design parameters such as back EMF, torque, phase inductance and power factor are readily calculated using the proposed methodology. This method is also used to optimise the geometry of a particular machine which provides an insight into the relationship between power factor and torque. Furthermore, the insights gained suggest a design approach that takes into account the power factor of TFMs, which may help unlock their potential through a trade-off between torque density and power factor. The results obtained using the analytical model are verified using 3D finite element analysis (FEA) and experimental data.
\end{abstract}

Index Terms-Permanent-magnet machines, transverse-flux machines, flux-linkage calculation, direct-drive machines, power factor.

\section{INTRODUCTION}

$\mathbf{T}$ RADITIONALLY, the renewable energy industry has been dominated by induction machines, synchronous machines and conventional radial or axial permanent magnet (PM) machines, which normally operate at high speed and low torque. Wind and marine turbines normally operate at low speed, around 5 to $25 \mathrm{rpm}$, making it necessary to install a gearbox in the drive-train to enable the use of a conventional generator [1], [2], [3], [4], [5]. Several novel machines have been designed to operate as direct-drive generators in renewable energy sources but they are not widespread across the industry [6], [7], [8], [9]. Transverse flux machines (TFMs), which sometimes are called variable-reluctance permanentmagnet (VRPM) machines, can achieve a high torque density which makes them an interesting option for direct-drive operation [10], [11], [12], [13], [14], [15], [16], [17]. However, TFMs tend to have a complicated topology with a threedimensional flux path, which makes the task of modelling and understanding the behaviour of these devices difficult. Additionally, TFMs tend to have a low power factor, which has hindered their acceptance [18], [19].

The current trend to study machines with complicated geometries such as TFMs [20], [21], [22], [23], [24], [25], [26], [27], [28], [29] and claw pole machines [30], [31], [32],

The authors are with the Mechatronics Research Group, Engineering Sciences, Faculty of Engineering and the Environment, University of Southampton, Highfield Campus Southampton SO17 1BJ, United Kingdom (e-mail: j.renedo-anglada@ soton.ac.uk; suleiman@ soton.ac.uk).

Jaime Renedo Anglada is with the Department of Technology, European Organization for Nuclear Research (CERN), Geneva 1211, Switzerland, since March 2017 (e-mail: jaime.renedo@ cern.ch).
[33], [34] is to use 3D CAD modelling and numerical methods like finite element analysis (FEA). This approach produce accurate results but does not provide an insight as deep as that provided by analytical methods.

Previous studies have successfully calculated the torque produced by TFMs by replacing the magnets with equivalent current sheets [35] and applying the BiL principle to obtain the torque; in this case $B$ is the stator's magnetic field and $i$ the equivalent current of the magnets [12], [13], [15], [14], [16], [36]. The relationship between torque and power factor was studied in [19]. However, in that publication the amplitude of the back emf was simply estimated by conservation of energy and the flux linkage was not calculated formally.

This paper presents an alternative analytical methodology for TFMs based on a virtual mutual inductance, $\mathfrak{M}$, between the equivalent current loops of PMs and the stator windings. This virtual mutual inductance can be used to calculate the flux linkage, back EMF and power factor of the machine using only the stator's magnetic field distribution.

The virtual mutual inductance approach presented in this paper provides a very deep insight into the behaviour of TFMs because the path of the stator's magnetic field is simpler than that of the PMs. Therefore, the calculation of the flux linkage using the virtual mutual inductance, $\mathfrak{M}$, is more intuitive and the relationship between torque and power factor can be readily understood. Understanding this relationship can be the key to unlocking the full potential of TFMs through a trade-off between torque density and power factor.

The paper starts with a description of a particular TFM in section II, which is used as a case study. Section III describes the virtual mutual inductance approach including the validation of the methodology using FEA and experimental data. The circuit parameters and performance of the machine under study obtained using the virtual mutual inductance approach are calculated in section IV. In section V torque and power factor are shown to be strongly interlinked; the implications of this on the design of TFMs are discussed. Finally, conclusions are drawn in section VI.

\section{DESCRIPTION OF THE MACHINE UNDER STUdY}

The magnetic topology of this machine is similar to that of claw-pole machines. Fig. 1 shows the radial and axial crosssections of the machine built at the University of Southampton [12], [13], [14], [15], [16]. The stator has two phases comprising a circular coil each, linking and magnetising 20 laminated C-cores which modulate the armature's magnetic field to produce a fundamental heteropolar (40 poles) harmonic 
in the radial direction. The number and width of the $\mathrm{C}$-cores has been carefully selected to maximise the flux utilisation factor and the torque produced by the machine.

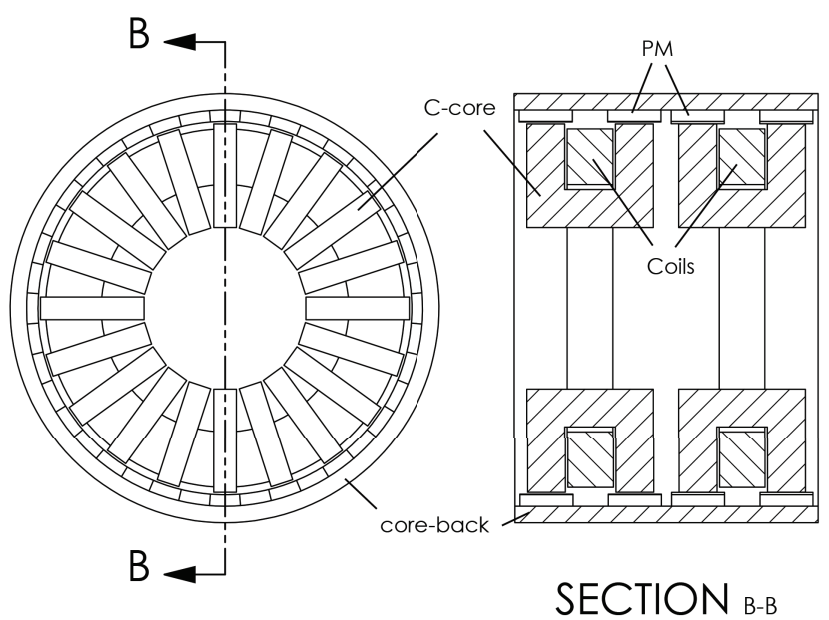

Fig. 1. Front view and cross-section of a single sided TFM.

The outer rotor comprises a cylindrical yoke with 4 arrays of 40 heteropolar magnets each, glued to the inside surface. Each phase is associated with two arrays of magnets: one array positioned over the left-hand $\mathrm{C}$-core legs and the other array, which is spatially anti-phase with the first, is positioned over the right-hand C-core legs. The two sets of magnet arrays corresponding to the two phases are spatial shifted by 90 electrical degrees (alternatively, the two sets of C-cores could be spatially shifted by 90 electrical degrees). The radial heterpolar flux harmonic interact with the magnets to produce useful torque. The aligned position is defined as the position of the rotor in which the flux passing through the C-cores is maximum.

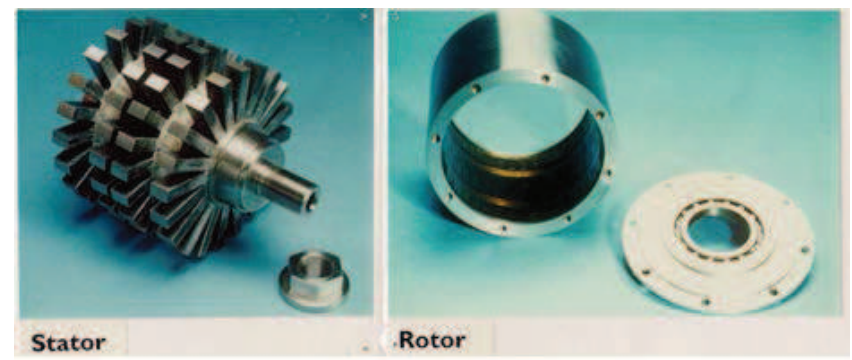

Fig. 2. Picture of the stator and the rotor of the TFM under study.

Fig. 2 shows a picture of the prototype machine. The key geometrical parameters of this device are shown in table I, which also defines the symbols used. The value of the total magnetic gap, $g_{z}$, is calculated as

$$
g_{z}=d_{m}+c_{g} .
$$

The magnets' axial length is greater than the teeth's axial length because the fringing flux in the axial direction crosses the air-gap and produces torque [36]. To estimate the active length of the C-core in the axial direction we can use results from [37] to estimate the tooth-to-yoke permeance of the Ccore head. Using this value of the permeance the total flux in
TABLE I

PARAMETERS OF THE TFM

\begin{tabular}{lcc}
\hline Quantity & Symbol & Value \\
\hline Stator radius & $R_{s}$ & $73 \mathrm{~mm}$ \\
Rotor radius & $R_{r}$ & $78.5 \mathrm{~mm}$ \\
Clearance gap & $c_{g}$ & $1 \mathrm{~mm}$ \\
Magnet thickness & $d_{m}$ & $4.5 \mathrm{~mm}$ \\
Magnet axial length & $L_{m a g}$ & $21 \mathrm{~mm}$ \\
C-core head width & $l_{c o r e}$ & $15 \mathrm{~mm}$ \\
C-core axial length & $w_{s}$ & $50 \mathrm{~mm}$ \\
C-core height & $h_{s}$ & $41 \mathrm{~mm}$ \\
C-core slot width & $w_{c}$ & $20 \mathrm{~mm}$ \\
C-core slot height & $h_{c}$ & $24 \mathrm{~mm}$ \\
Winding clearance & $h_{c o}$ & $2 \mathrm{~mm}$ \\
Pole pitch & $\theta_{\lambda}$ & $18^{\circ}$ \\
Tooth pitch & $\theta_{t}$ & $7.02^{\circ}$ \\
Slot pitch & $\theta_{s}$ & $10.98^{\circ}$ \\
Number of C-cores & $N_{c}$ & 20 \\
Number of turns & $N_{w}$ & 230 \\
Number of phases & $q$ & 2 \\
Magnetisation & $\mathcal{M}$ & $\sim 796 \mathrm{kA} / \mathrm{m}$ \\
\hline
\end{tabular}

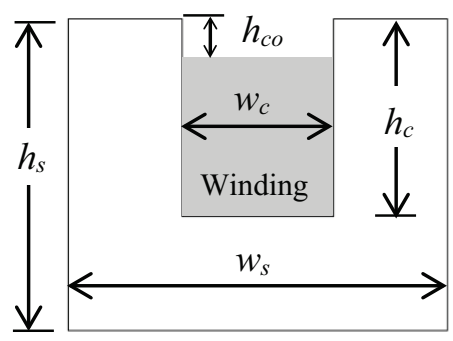

Fig. 3. Dimensions of the C-core in detail.

a tooth can be directly calculated. This enables the calculation of an effective axial length of a tooth, $L$, or model depth of an equivalent 2 dimensional radial model of the machine. Accordingly, the effective length of a tooth, $L$, takes into account the fringing flux and is calculated as follows:

$$
L \approx l_{\text {core }}\left(1+0.384 \frac{g_{z}}{l_{\text {core }}}\right) .
$$

The above expression can also be applied to estimate the value of the magnets' axial length, $L_{\text {mag }}$, during the design process.

\section{Virtual Mutual Inductance Approach}

The flux linkage in the stator windings of PM machines is normally obtained after calculating the PMs' magnetic field distribution in the air-gap and integrating the flux density over the coils surfaces.

In the virtual mutual inductance approach the magnets are replaced with equivalent current sheets [35]. Fig. 4 shows schematically the air-gap of the TFM with a radially magnetised PM with its equivalent current sheets. In this context, when the rotor moves the relative position of the stator windings and the equivalent current sheets changes. These current sheets can be thought of as several current loops in series.

The reciprocity theorem states that for any two circuits the value of the mutual inductances is the same, this is $\mathfrak{M}_{12}=$ $\mathfrak{M}_{21}$, regardless of the geometry [38], [39]. Therefore, if the 


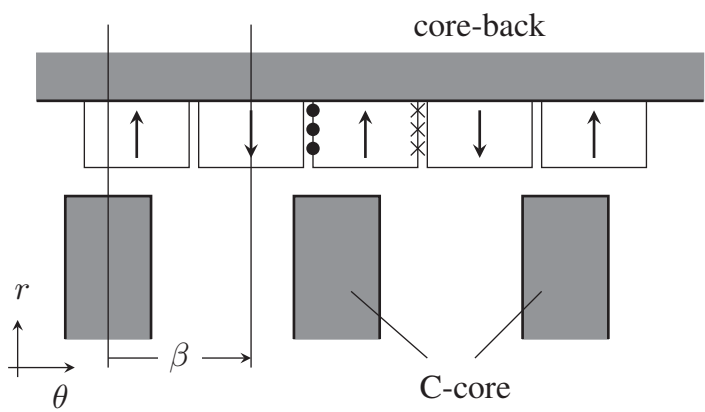

Fig. 4. Schematic view of the air-gap of the TFM under study with the equivalent current loops at a particular position of the rotor, $\beta$.

stator's magnetic field distribution in the air-gap of the TFM under study is known, then flux linking the equivalent current sheets due to the stator's MMF can be directly calculated as

$$
\lambda_{P M}=\int_{P M} N_{P M} \vec{B}(\theta, r) \cdot d \vec{a}=\mathfrak{M}(\beta) \cdot I_{S},
$$

where $\vec{B}(\theta, r)$ is the magnetic field distribution produced by the stator's windings, $N_{P M}$ is the number of turns of the equivalent current loop which is $1, I_{S}$ the stator's current and $\mathfrak{M}(\beta)$ the virtual mutual inductance between the stator windings and the equivalent current sheets, at a particular rotor position $\beta$. Based on the reciprocity theorem the flux linkage of the stator windings due to the PMs can be calculated as

$$
\lambda_{S}=\mathfrak{M}(\beta) \cdot I_{P M},
$$

where $I_{P M}$ is the equivalent current of the PMs,

$$
I_{P M}=\mathcal{M} \cdot d_{m}
$$

where $\mathcal{M}$ is the magnetisation and $d_{m}$ the magnet's thickness.

\section{A. Calculation of the Virtual Mutual Inductance}

The total virtual mutual inductance, $\mathfrak{M}(\beta)$, is calculated as the average of the virtual mutual inductance of single coils, $\mathfrak{M}_{s c}(\beta, r)$, along the magnet thickness.

Let us consider two consecutive permanent magnets of a TFM. Fig. 5 shows a single equivalent coil in the relative position $\beta$ in the air-gap.

Using the complex permeance function defined in [40], the magnetic field distribution in the air-gap produced by the stator can be expressed in polar coordinates ( $\theta$ is the electrical angle in radians) as

$$
\begin{array}{r}
\vec{B}(\theta, r)=B_{s} \frac{R_{g}}{r}\left[\bar{\lambda}_{r}\left\{1+\sum_{1}^{\infty} \gamma_{n}(r) \cos (n \theta)\right\} \vec{u}_{r}\right. \\
\left.+\sum_{1}^{\infty} \lambda_{\theta n}(r) \sin (n \theta) \vec{u}_{\theta}\right]
\end{array}
$$

where

$$
B_{s}=\frac{\mu_{e q} \mu_{0} F}{g_{z}}
$$

$F$ is the MMF across the air-gap of value $F=N_{w} I_{S} / 2$, $\mu_{e q}$ is the equivalent permeability calculated using reluctance

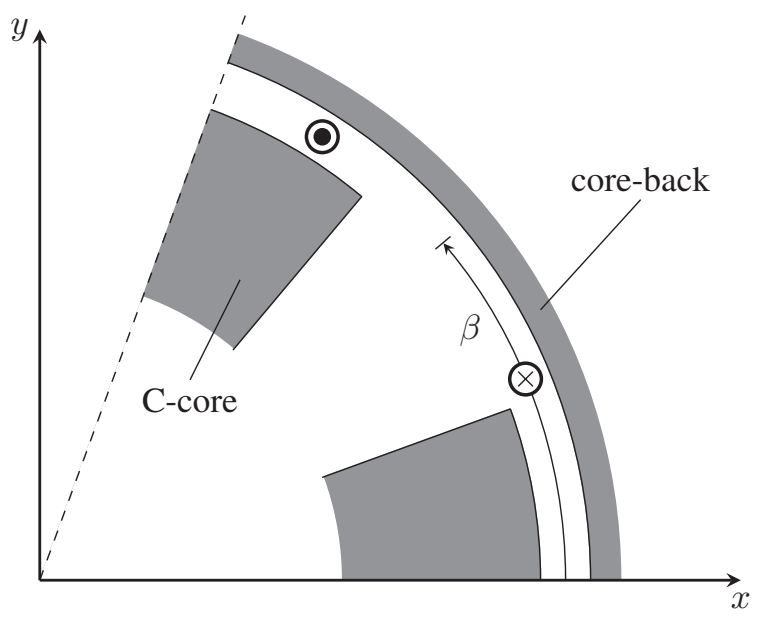

Fig. 5. Schematic view of a single coil in the air-gap at the position $\beta$.

networks, which depends on the relative permeability of the PMs $\left(\mu_{r}\right)$ and the magnet thickness to effective air-gap ratio [41]. It is calculated as follows:

$$
\mu_{e q}=\mu_{r}\left(\frac{g_{z}}{d_{m}+\mu_{r} c_{g}}\right) .
$$

The total flux linkage through the circuit that corresponds to one pole pair is the contribution of two loops in series, the first one is positive and the second one is negative according to the direction of magnetisation of the magnets. The expression of the flux linkage over $N_{c}$ pairs of poles, taking into account that each $\mathrm{C}$-core has two heads, is therefore given by

$$
\begin{aligned}
& \lambda_{P M}(\beta, r)= \\
& 2 N_{c}\left[\int_{\beta-\frac{\pi}{2}}^{\beta+\frac{\pi}{2}} B_{r}(\theta, r) \frac{L r}{N_{c}} d \theta-\int_{\beta+\frac{\pi}{2}}^{\beta+\frac{3 \pi}{2}} B_{r}(\theta, r) \frac{L r}{N_{c}} d \theta\right],
\end{aligned}
$$

where $L$ is the equivalent length of the magnets in the axial direction and $N_{c}$ the number of C-cores.

The final expression of the flux linkage of a single coil is

$$
\begin{aligned}
\lambda_{P M}(\beta, r) & =8 L R_{g} B_{s} \bar{\lambda}_{r}\left[\frac{\gamma_{1}(r)}{1} \cos (\beta)\right. \\
& \left.-\frac{\gamma_{3}(r)}{3} \cos (3 \beta)+\frac{\gamma_{5}(r)}{5} \cos (5 \beta)-\ldots\right] .
\end{aligned}
$$

Now that the total flux linking with the equivalent currents of the PMs is known, the expression of the virtual mutual inductance of a single current loop becomes

$$
\begin{aligned}
\lambda_{P M}(\beta, r)= & \mathfrak{M}_{s c}(\beta, r) I_{S} \\
& \Rightarrow \mathfrak{M}_{s c}(\beta, r)=\lambda_{P M}(\beta, r) \frac{\mu_{e q} \mu_{0} N_{w}}{2 g_{z} B_{s}} .
\end{aligned}
$$

The final expression of the virtual mutual inductance between a coil at a distance $r$ and position $\beta$ can be shown to be given by:

$$
\begin{aligned}
& \mathfrak{M}_{s c}(\beta, r)= \\
& \quad 4 \mu_{e q} \mu_{0} \frac{R_{g} L N_{w}}{g_{z}} \bar{\lambda}_{r} \sum_{1,3,5 \ldots}^{\infty} \frac{\gamma_{n}(r)}{n} \cos (n \beta)(-1)^{\frac{n-1}{2}} .
\end{aligned}
$$


The virtual mutual inductance for the distributed equivalent current of the magnets with thickness $d_{m}$ can be calculated as follows:

$$
\mathfrak{M}(\beta)=\frac{1}{d_{m}} \int_{0}^{d_{m}} \mathfrak{M}_{s c}(\beta, \delta) d \delta,
$$

where $\delta$ is the distance to the core-back:

$$
\delta=R_{g}+\frac{g_{z}}{2}-r .
$$

The final expression of the virtual mutual inductance will then be given by

$\mathfrak{M}(\beta)=4 \mu_{e q} \mu_{0} \frac{R_{g} L N_{w}}{g_{z}} \bar{\lambda}_{r} \sum_{1,3,5 \ldots}^{\infty} \frac{\gamma_{n}^{a v}}{n} \cos (n \beta)(-1)^{\frac{n-1}{2}}$,

where $\gamma_{n}^{a v}$ is the average value of $\gamma_{n}(r)$ along the magnet thickness.

\section{B. Validation of the Methodology}

The results of the analytical model are compared with experimental data and 3D FEA. The flux linkage of the stator winding was measured using a flux meter while manually rotating the rotor over 18 mechanical degrees, which corresponds to 360 electrical degrees.

Fig. 6 shows a quarter model of the TFM under study with the magnetic field passing through one C-core. The 3D model was simulated using magnetostatic FEA for several rotor positions. The flux linkage is calculated by integrating the magnetic field through the C-core back, as shown schematically in Fig. 6.

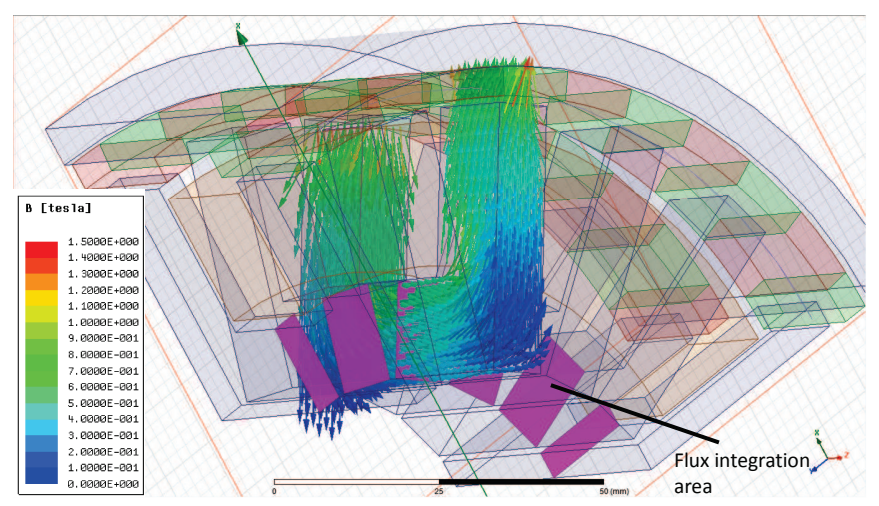

Fig. 6. Magnetic field passing through a C-core, 3D FEA model.

Fig. 7 shows the flux linkage obtained analytically, the experimental data and the 3D FEA data. It can be appreciated that the analytical method underestimates the amplitude of the flux linkage. This is probably due to the 3-dimensional interaction of the field around the C-core head, which is only partly taken into account by using the equivalent length, $L$.

The definition of the equivalent length, $L$, used in this paper is similar to the magnetic length, $l_{\text {mag }}$, commonly used in the design of electromagnets for particle accelerators [42], [43], [44]. The magnetic length, $l_{\text {mag }}$, takes into account the fact that the fringing flux at the end of the poles increases the integrated field along the axis of the beam, which is the bending power in a dipole for example. During the initial stages of the design process of a magnet, the value of $l_{m a g}$ can be estimated using the following heuristic expression:

$$
l_{\text {mag }}=l_{\text {iron }}+k h,
$$

where $l_{\text {iron }}$ is the axial length of the iron yoke, $h$ is the aperture (or air-gap) of the magnet and $k$ is a constant whose values are typically between 0.3 and 0.6. The expression for the equivalent length shown in (2) has a similar shape to the above expression but it underestimates slightly the contribution of the fringing flux. Therefore, the expression shown in (2) is useful for a first conservative estimation of the flux, which is consistent with the results shown in Fig. 7.

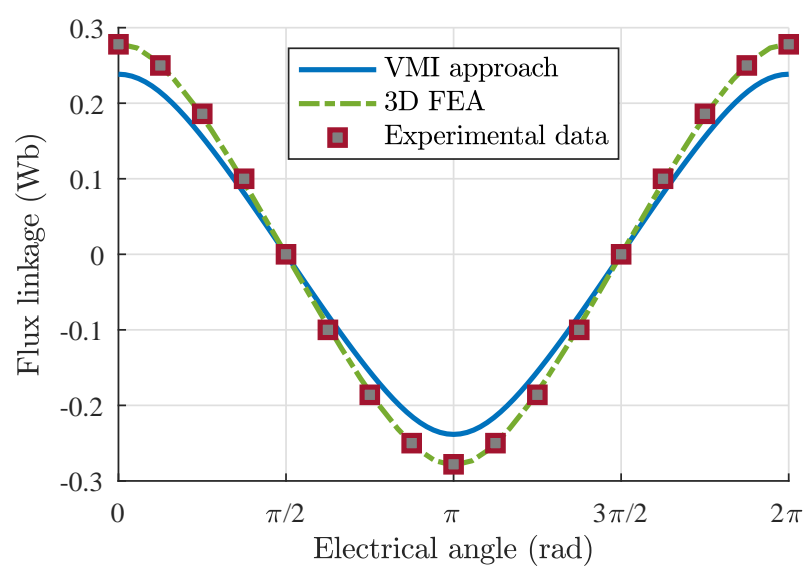

Fig. 7. Flux linkage versus rotor angle obtained using 3D FEA, experimental data and the proposed flux linkage equation using the virtual mutual inductance (VMI) approach.

\section{Circuit Parameters AND PerformanCE}

\section{A. Back EMF and Torque Constants}

The instantaneous back EMF each phase can be obtained directly using Faraday's Law. Therefore, the induced voltage for a given electrical frequency $\omega$ can be expressed as follows:

$$
\mathcal{E}_{S}(t)=-\frac{d \lambda_{S}(\omega t)}{d t}=-I_{P M} \frac{d \mathfrak{M}(\omega t)}{d t},
$$

which can be rewritten as

$$
\begin{aligned}
& \mathcal{E}_{S}(t)= \\
& 4 \mu_{e q} \mu_{0} N_{w} \frac{R_{g} L}{g_{z}} \bar{\lambda}_{r} I_{P M} \omega \sum_{1,3,5 \ldots}^{\infty} \frac{\gamma_{n}^{a v}}{n} \sin (n \omega t)(-1)^{\frac{n-1}{2}} .
\end{aligned}
$$

The RMS value of the fundamental harmonic when the machine is operating in the steady state at constant speed is expressed as

$$
E_{R M S}=\frac{4 \mu_{e q} \mu_{0}}{\sqrt{2}} N_{w} \frac{R_{g} L}{g_{z}} \bar{\lambda}_{r} I_{P M} \gamma_{1}^{a v} \omega
$$

which can be expressed using the back EMF constant, $k_{E}$, [41] as

$$
E_{R M S}=k_{E} \Omega
$$


where $\Omega=\omega / N_{c}$ is the mechanical speed of the rotor. This gives the following expression for the back EMF constant

$$
k_{E}=\frac{4 \mu_{e q} \mu_{0}}{\sqrt{2}} N_{w} N_{c} \frac{R_{g} L}{g_{z}} \bar{\lambda}_{r} I_{P M} \gamma_{1}^{a v} .
$$

On the other hand, the average torque per phase can be obtained using the torque equation in [36]. The average torque per phase when the current is sinusoidal is given by

$$
T_{p h}=\frac{4 \mu_{e q} \mu_{0}}{\sqrt{2}} N_{w} N_{c} \frac{R_{g} L}{g_{z}} \bar{\lambda}_{r} I_{P M} \gamma_{1}^{a v} I_{R M S},
$$

which can be rewritten as

$$
T_{p h}=k_{T} I_{R M S},
$$

where $k_{T}$ is the torque constant [41] calculated as follows

$$
k_{T}=\frac{4 \mu_{e q} \mu_{0}}{\sqrt{2}} N_{w} N_{c} \frac{R_{g} L}{g_{z}} \bar{\lambda}_{r} I_{P M} \gamma_{1}^{a v} .
$$

As expected the expressions of (21) and (24) are exactly the same, with the only particularity that for TFMs the back EMF constant is equal to the torque constant per phase.

\section{B. Phase Inductance}

The reactance is due to the self-inductance of the coils, it can be separated into two different terms one due to the flux that crosses the air-gap, $L_{g}$, and one due to the leakage in the axial direction, $L_{l}$.

The value of $L_{g}$ can be estimated using the expression of the magnetic field distribution in the air-gap to obtain the flux. For a given current $i$ the inductance is calculated as follows:

$$
L_{g}=N_{c} \frac{N_{w} \Phi_{\text {core }}}{i},
$$

where $\Phi_{\text {core }}$ is the total flux passing through one C-core across the air-gap. The parameter $\bar{\lambda}_{r}$ from the complex permeance function in (6) can be used to obtain the total flux crossing the air-gap as follows

$$
\Phi_{\text {core }}=\hat{B} \bar{\lambda}_{r} L \frac{2 \pi R_{g}}{N_{c}},
$$

with

$$
\hat{B}=\frac{\mu_{e q} \mu_{0} N_{w} i}{2 g_{z}},
$$

therefore, the final expression of the air-gap inductance is

$$
L_{g}=\mu_{e q} \mu_{0} N_{w}^{2} L \frac{\pi R_{g} \bar{\lambda}_{r}}{g_{z}} .
$$

In addition to the air-gap inductance it is important to calculate the leakage inductance due to the leakage flux, which tends to be significant in TFMs. The leakage flux in the axial direction can be estimated using the classical expression for the slot leakage, which can be found in [45]. Therefore, the leakage inductance is calculated as follows:

$$
L_{l}=\mu_{0} N_{c} N_{w}^{2} l_{\text {core }}\left(\frac{h_{c}-h_{c o}}{3 w_{s}}+\frac{h_{c o}}{w_{s}}\right),
$$

where $h_{c}$ is the slot depth, $h_{c o}$ is the difference between the slot depth and the coil depth, $w_{s}$ the slot width, and $l_{\text {core }}$ the C-core axial length as shown in Fig. 3.
The total reactance $X$ takes into account the air-gap inductance (obtained using the virtual mutual inductance approach) and the leakage inductance (obtained using classical formulae), it is calculated as follows

$$
X=\omega\left(L_{g}+L_{l}\right)
$$

\section{Power Factor}

The back EMF can be calculated using (20) and the reactance can be calculated according to (30). Therefore, the power factor can be directly calculated. TFMs tend to have a low power factor; in [18] this topic is studied in detail. The conclusion is that besides the leakage, which is relatively high in these machines, the main cause of the low power factor of TFMs is their ineffective use of magnetic flux [19]. This can be easily seen in the fact that during the calculation of the virtual mutual inductance one of the equivalent current loops has a strong positive flux linking while the flux linking with the other current loop is in the opposite direction. However, many publications state that the low power factor is due to leakage in the classical way [46], [47], [48], [49], [50]. Leakage has been defined traditionally as the part of the flux that does not cross the air-gap [45], [51], [52], [53]; the negative flux mentioned earlier is actually crossing the air-gap but in the opposite direction. This matter is studied in more detail in section $\mathrm{V}$.

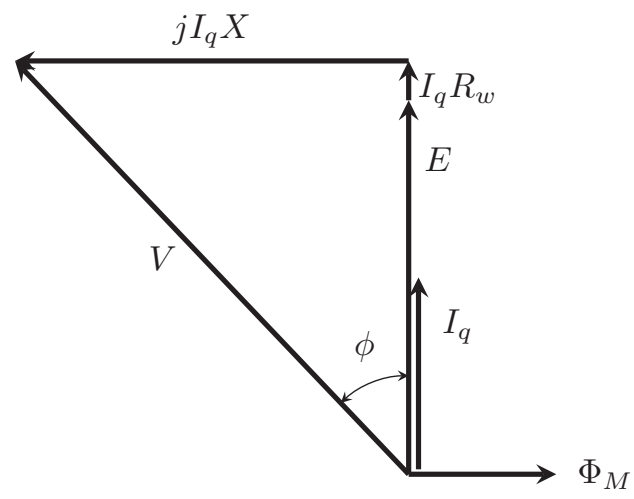

Fig. 8. Phasor diagram with current only in the quadrature axis.

To operate in maximum torque condition the current, $I$, has to be in phase with the back EMF, $E$; this means that current only has a q-axis component $I_{q}$. The phasor diagram is shown in Fig. 8.

At high frequencies the value of $X$ is much greater than the value of the resistance of the windings, $R_{w}$. Therefore, the angle $\phi$ in Fig. 8 can be approximated as

$$
\phi \approx \tan ^{-1}\left(\frac{I_{q} X}{E}\right) .
$$

Since both the back EMF and the phase inductance are proportional to the frequency the power factor operating with the rated current is independent of the frequency.

\section{Electrical Parameters of the Machine}

The proposed method was used to calculate the back emf, and air-gap inductance as shown in Table II, which also includes the other electrical parameters of the machine. 
TABLE II

ELECTRICAL PARAMETERS OF THE TFM

\begin{tabular}{lcc}
\hline Quantity & Symbol & Value \\
\hline Rated current & $I$ & $10 \mathrm{~A}$ \\
Back emf constant & $k_{E}$ & $3.54 \mathrm{~V} /(\mathrm{rad} / \mathrm{s})$ \\
Torque constant & $k_{T}$ & $3.54 \mathrm{Nm} / \mathrm{A}$ \\
Air-gap inductance & $L_{g}$ & $40.5 \mathrm{mH}$ \\
Leakage inductance & $L_{l}$ & $5.9 \mathrm{mH}$ \\
Phase resistance & $R_{w}$ & $1.57 \Omega$ \\
Power factor & $\cos (\phi)$ & 0.35 \\
\hline
\end{tabular}

\section{Design TRADE-OFFS}

Taking the machine described in section II as a starting point, let us show how to choose the number of C-cores, which is also the number of pole pairs. Assuming that the radius of the machine $R_{g}$, the magnet thickness $d_{m}$, the clearance gap $c_{g}$ and the tooth-pitch ratio $t / \tau_{p}$ remain constant. The pole pitch is calculated as follows:

$$
\tau_{p}=\frac{2 \pi R_{g}}{N_{c}}
$$

With these constraints it is possible to calculate the parameters of the machine (average torque, back EMF and power factor at full load) starting from $N_{c}=1$ until $N_{c}=35$. Also, the maximum power factor (which corresponds to the power factor assuming no leakage, $L_{l}=0 \mathrm{H}$ ) is calculated. The purpose of this is to show that while leakage affects the power factor it is not the main cause of the low power factor in TFMs.

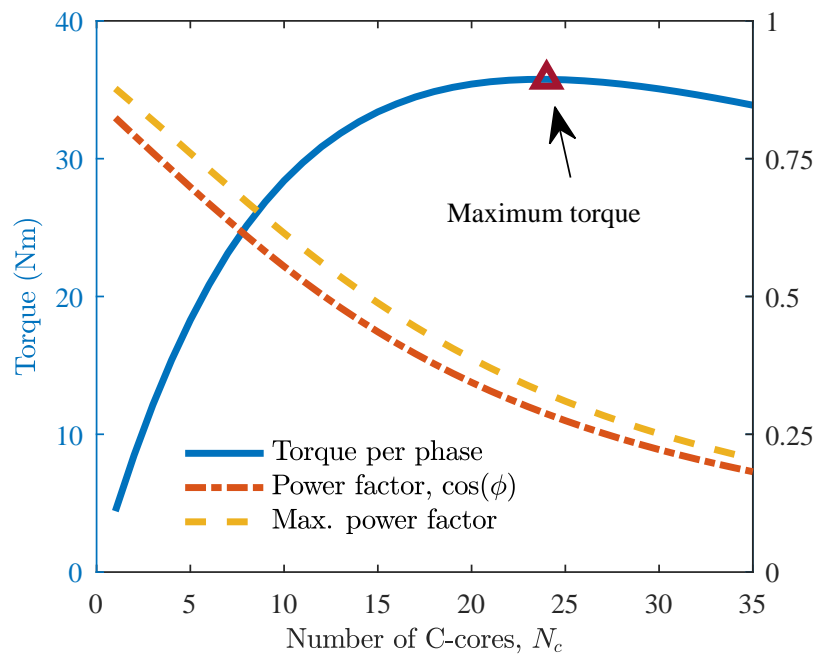

Fig. 9. Average torque per phase and power factor as a function of the number of C-cores.

Fig. 9 shows the average torque per phase, calculated using (23), as a solid line with the scale on the left hand side of the graph. As the number of $\mathrm{C}$-cores increases the average torque also increases until it reaches a maximum point, which corresponds to $N_{c}=24 \mathrm{C}$-cores. The power factor at full load and the maximum power factor are shown in Fig. 9 with the scale on the right hand side of the graph. It can be easily appreciated that the maximum power factor is higher than the actual power factor but it follows the same strictly decreasing trend.

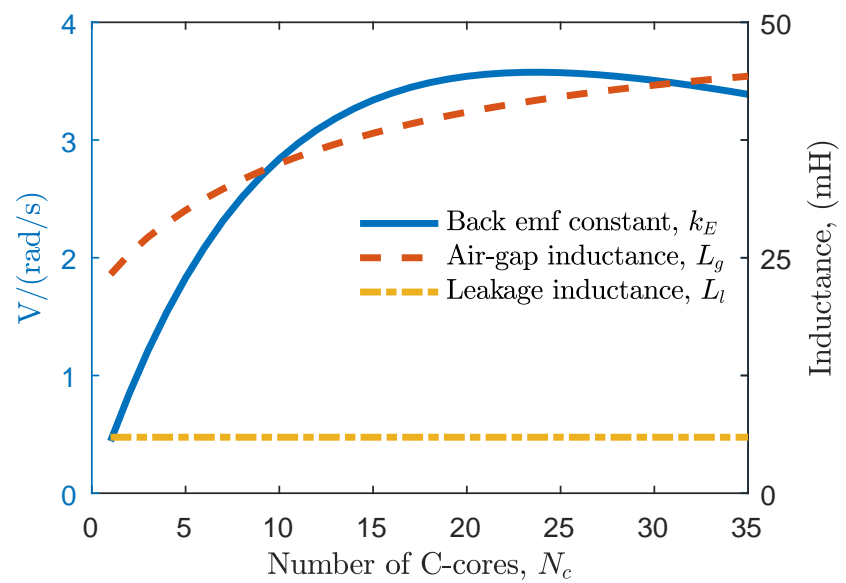

Fig. 10. Air-gap inductance, $L_{g}$, leakage inductance, $L_{l}$, and back emf constant, $k_{E}$, as a function of the number of C-cores.

The air-gap inductance, $L_{g}$, leakage inductance, $L_{l}$, and back emf constant, $k_{E}$, as a function of the number of $\mathrm{C}$ cores are shown in Fig. 10. It can be appreciated that the back emf constant follows the same trend as the average torque (as shown in Fig. 9), which is not surprising since the torque constant and the back emf constant are equal. On the other hand, the air-gap inductance increases gradually with the number of $\mathrm{C}$-cores and the leakage inductance remains constant. Therefore, leakage understood in the classical way is not the cause of the low power factor of these machines.

Let the base impedance be defined as the ratio of the back emf, $E$, to the rated current, $I_{b}$, as follows:

$$
Z_{b}=\frac{E}{I_{b}}
$$

Accordingly, the air-gap and leakage reactance are calculated in per unit as follows:

$$
\begin{gathered}
x_{g}=\frac{X_{g} I_{b}}{E}=\frac{2 \pi f L_{g} I_{b}}{E}, \\
x_{l}=\frac{X_{l} I_{b}}{E}=\frac{2 \pi f L_{l} I_{b}}{E},
\end{gathered}
$$

and the total reactance is simply:

$$
x_{t o t}=x_{g}+x_{l}=\frac{\left(X_{g}+X_{l}\right) I_{b}}{E} .
$$

The power factor at full load is calculated using the phasor diagram shown in Fig. 8, with $I_{q}=I_{b}$, and if the term $I_{q} R_{w}$ is small compared to the back emf, then it is frequency independent. It can be appreciated that the expression of $x_{t o t}$ shown in (36) is closely related to the power factor, as pointed out in (31). In simple terms, if $x_{t o t}$ increases, then $\phi$ tends to increase and the power factor tends to decrease.

Fig. 11 shows the total reactance, $x_{t o t}$, and air-gap reactance, $x_{g}$ in per unit as a function of the number of C-cores. It can be appreciated that as the number of $\mathrm{C}$-cores increases the total reactance, $x_{t o t}$, increases, which implies a decrease in the power factor at full load. Furthermore, the air-gap inductance, 


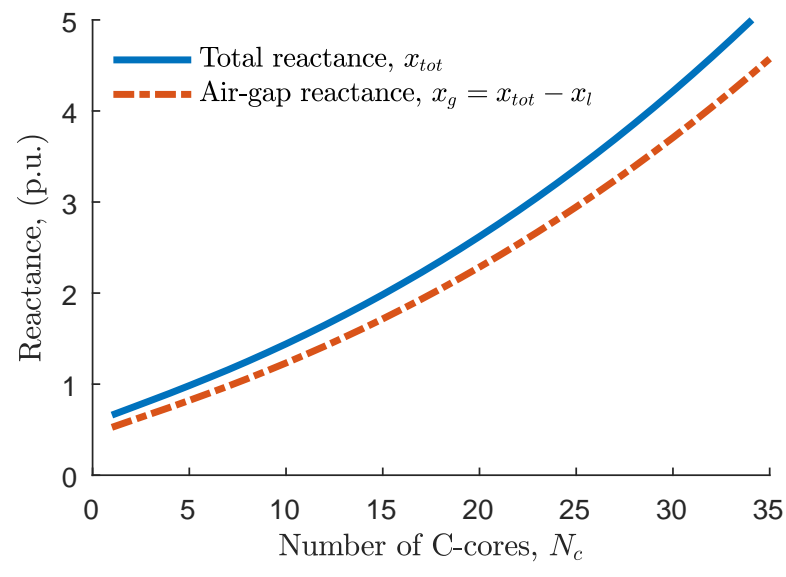

Fig. 11. Total reactance, $x_{t o t}$, and air-gap reactance, $x_{g}$ in per unit as a function of the number of $\mathrm{C}$-cores.

$x_{g}$, follows the same trend, therefore the maximum theoretical power factor (which is calculated assuming no leakage flux, $\left.L_{l}=0 \mathrm{H}\right)$ also decreases significantly; this is consistent with the results shown in Fig. 9. The sharp increase in $x_{t o t}$ can be explained as follows: if the mechanical speed is constant, each additional C-core increases the back emf (when $N_{c}<24$ in our case). However, since there is one additional pair of poles the electrical frequency has to increase and so does the reactance. This shows that the low power factor of TFMs is not due to leakage in the classical way but due to the ineffective use of the magnetic flux as it was mentioned earlier in this paper and discussed in [18], [19].

If the design optimisation is done only considering torque, as many authors propose [48], [49], [50], the optimal machine would have $N_{c}=24 \mathrm{C}$-cores. However, this number of Ccores yields a very low power factor $(<0.3)$. Near $N_{c}=24$ $\mathrm{C}$-cores the slope of the torque curve is very low and the slope of the power factor curve is steep, which means that for small improvements of torque for each $\mathrm{C}$-core added there is a strong penalty in terms of power factor. The power factor can be improved considerably by reducing the number of $\mathrm{C}$ cores thus reducing the torque density slightly. Such a happy compromise between torque density and power factor may be the key to unlocking the potential of these machines.

\section{CONCLUSIONS}

This paper studies a TFM using an alternative methodology based on the concept of virtual mutual inductance. The proposed methodology is used to obtain key performance parameters of the machine such as back EMF, torque and power factor. These results are consistent with 3D FEA and experimental data.

It is shown that the low power factor of TFMs is not due to leakage in the traditional sense. It is due to the ineffective use of the magnetic flux, which can be directly deduced from the calculation of the virtual mutual inductance, $\mathfrak{M}(\beta)$. Furthermore, power factor can be improved significantly by reducing the number of $\mathrm{C}$-cores with a small impact on torque, which can be the key to unlocking the potential of these machines.

The proposed methodology was successfully applied to analyse a prototype TFM. However, the principle of the virtual mutual inductance approach is completely general and can be applied to any kind of PM machine.

\section{ACKNOWLEDGEMENT}

The authors would like to thank Dr. M. Yuratich and the team of TSL Technology Ltd. for their support during this project.

\section{REFERENCES}

[1] J. Sopanen, V. Ruuskanen, J. Nerg, and J. Pyrhonen, "Dynamic torque analysis of a wind turbine drive train including a direct-driven permanent-magnet generator," IEEE Transactions on Industrial Electronics, vol. 58, pp. 3859-3867, Sept 2011.

[2] H. Polinder, F. F. A. van der Pijl, G. J. de Vilder, and P. J. Tavner, "Comparison of direct-drive and geared generator concepts for wind turbines," IEEE Transactions on Energy Conversion, vol. 21, pp. 725733, Sept 2006.

[3] E. Spooner, P. Gordon, J. R. Bumby, and C. D. French, "Lightweight ironless-stator pm generators for direct-drive wind turbines," IEE Proceedings - Electric Power Applications, vol. 152, pp. 17-26, Jan 2005.

[4] M. A. Mueller, H. Polinder, and N. Baker, "Current and novel electrical generator technology for wave energy converters," in 2007 IEEE International Electric Machines Drives Conference, vol. 2, pp. 1401-1406, May 2007.

[5] R. S. Semken, M. Polikarpova, P. Roytta, J. Alexandrova, J. Pyrhonen, J. Nerg, A. Mikkola, and J. Backman, "Direct-drive permanent magnet generators for high-power wind turbines: benefits and limiting factors," IET Renewable Power Generation, vol. 6, pp. 1-8, January 2012.

[6] H. Polinder, J. A. Ferreira, B. B. Jensen, A. B. Abrahamsen, K. Atallah, and R. A. McMahon, "Trends in wind turbine generator systems," IEEE Journal of Emerging and Selected Topics in Power Electronics, vol. 1, pp. 174-185, Sept 2013.

[7] B. Hamilton, M. Bielecki, C. Bloch, T. Decker, L. Frantzis, K. Midura, J. Paidipati, and F. Zhao, "Offshore Wind Market and Economic Analysis," tech. rep., National Renewable Energy Laboratory, September 2014.

[8] A. Smith, T. Stehely, and W. Musial, "2014-2015 Offshore Wind Technologies Market Report," tech. rep., National Renewable Energy Laboratory, June 2015.

[9] J. Carroll, A. McDonald, and D. McMillan, "Reliability comparison of wind turbines with dfig and pmg drive trains," IEEE Transactions on Energy Conversion, vol. 30, pp. 663-670, June 2015.

[10] H. Weh and R. Mayer, "Synchronous machine with permanent magnet excitation as a flexible propulsion motor with high efficiency," in Electrical Machines (ICEM), 1984 International Conference on, 1984.

[11] H. Weh and H. May, "Achievable force densities for permanent magnet excited machines in new configurations," in Electrical Machines (ICEM), 1986 International Conference on, 1986.

[12] M. R. Harris and B. C. Mecrow, "Variable reluctance permanent magnet motors for high specific output," in Electrical Machines and Drives, 1993. Sixth International Conference on (Conf. Publ. No. 376), pp. 437442, Sep 1993.

[13] M. R. Harris and G. H. Pajooman, "Electric motors with heteropolar permanent magnets and homopolar windings: computational study of performance limits," in Electrical Machines and Drives, 1995. Seventh International Conference on (Conf. Publ. No. 412), pp. 237-241, Sep 1995.

[14] M. R. Harris, G. H. Pajooman, and S. M. A. Sharkh, "Performance and design optimisation of electric motors with heteropolar surface magnets and homopolar windings," IEE Proceedings - Electric Power Applications, vol. 143, pp. 429-436, Nov 1996.

[15] M. R. Harris, G. H. Pajooman, and S. M. A. Sharkh, "Comparison of alternative topologies for vrpm (transverse-flux) electrical machines," in New Topologies for Permanent Magnet Machines (Digest No: 1997/090), IEE Colloquium on, pp. 2/1-2/7, Jun 1997.

[16] G. H. Pajooman, Performance assessment and design optimisation of VRPM (transverse flux) machines by finite element computation. $\mathrm{PhD}$ Thesis, University of Southampton, 1997. 
[17] G. Henneberger and M. Bork, "Development of a new transverse flux motor," in New Topologies for Permanent Magnet Machines (Digest No: 1997/090), IEE Colloquium on, pp. 1/1-1/6, Jun 1997.

[18] M. R. Harris, G. H. Pajooman, and S. M. A. Sharkh, "The problem of power factor in vrpm (transverse-flux) machines," in Electrical Machines and Drives, 1997 Eighth International Conference on (Conf. Publ. No. 444), pp. 386-390, Sep 1997.

[19] J. R. Anglada and S. M. Sharkh, "An insight into torque production and power factor in transverse-flux machines," IEEE Transactions on Industry Applications, vol. 53, pp. 1971-1977, May 2017.

[20] J. F. Gieras, "Performance characteristics of a transverse flux generator," in IEEE International Conference on Electric Machines and Drives, 2005., pp. 1293-1299, May 2005.

[21] O. Keysan, M. Mueller, A. McDonald, N. Hodgins, and J. Shek, "Designing the c-gen lightweight direct drive generator for wave and tidal energy," Renewable Power Generation, IET, vol. 6, pp. 161-170, May 2012

[22] D. H. Kang and H. Weh, “3D-FEM Analysis Versus Test Results for Three Transversal Flux Linear Motor Topologies," Electric Power Components and Systems, vol. 36, pp. 345-358, Mar. 2008.

[23] G. Yang, D. Cheng, H. Zhang, and B. Kou, "Bidirectional crosslinking transverse flux permanent magnet synchronous motor," IEEE Transactions on Magnetics, vol. 49, pp. 1242-1248, March 2013.

[24] N. J. Baker, S. Cawthorne, E. Hodge, and E. Spooner, "3d modelling of the generator for openhydro's tidal energy system," in Power Electronics, Machines and Drives (PEMD 2014), 7th IET International Conference on, pp. 1-6, April 2014.

[25] H. Zhang, B. Kou, W. Zhao, and G. Yang, "Design and analysis of a bidirectional cross-linking transverse flux permanent magnet synchronous motor," in Electromagnetic Launch Technology (EML), 2014 17th International Symposium on, pp. 1-6, July 2014.

[26] J. Doering, G. Steinborn, and W. Hofmann, "Torque, power, losses, and heat calculation of a transverse flux reluctance machine with soft magnetic composite materials and disk-shaped rotor," IEEE Transactions on Industry Applications, vol. 51, pp. 1494-1504, March 2015.

[27] C. Liu, J. Zhu, Y. Wang, Y. Guo, G. Lei, and X. Liu, "Development of a low-cost double rotor axial flux motor with soft magnetic composite and ferrite permanent magnet materials," Journal of Applied Physics, vol. 117, no. 17, 2015.

[28] Z. Wan, A. Ahmed, I. Husain, and E. Muljadi, "A novel transverse flux machine for vehicle traction aplications," in 2015 IEEE Power Energy Society General Meeting, pp. 1-5, July 2015.

[29] O. Dobzhanskyi and R. Gouws, "Performance analysis of a permanent magnet transverse flux generator with double coil," IEEE Transactions on Magnetics, vol. 52, pp. 1-11, Jan 2016.

[30] J. G. Washington, G. J. Atkinson, N. J. Baker, A. G. Jack, B. C Mecrow, B. B. Jensen, L. Pennander, G. Nord, and L. Sjoberg, "An improved torque density modulated pole machine for low speed high torque applications," in Power Electronics, Machines and Drives (PEMD 2012), 6th IET International Conference on, pp. 1-6, March 2012.

[31] N. J. Baker, G. J. Atkinson, J. G. Washington, B. C. Mecrow, G. Nord, and L. Sjoberg, "Design of high torque traction motors for automotive applications using modulated pole smc machines," in Power Electronics, Machines and Drives (PEMD 2012), 6th IET International Conference on, pp. 1-6, March 2012.

[32] N. Ahmed, J. Washington, G. J. Atkinson, and N. J. Baker, "Reduction of cogging torque and torque ripple in modulated pole machines by geometrical changes," in Power Electronics, Machines and Drives (PEMD 2014), 7th IET International Conference on, pp. 1-6, April 2014.

[33] R. P. Deodhar, A. Pride, and J. J. Bremner, "Design method and experimental verification of a novel technique for torque ripple reduction in stator claw-pole pm machines," IEEE Transactions on Industry Applications, vol. 51, pp. 3743-3750, Sept 2015.

[34] J. G. Washington, G. J. Atkinson, and N. J. Baker, "Reduction of cogging torque and emf harmonics in modulated pole machines," IEEE Transactions on Energy Conversion, vol. 31, pp. 759-768, June 2016.

[35] N. Boules, "Prediction of no-load flux density distribution in permanent magnet machines," IEEE Transactions on Industry Applications, vol. IA21, pp. 633-643, May 1985.

[36] J. Anglada and S. Sharkh, "Analytical Calculation of the Torque Produced by Transverse Flux Machines," IET Electric Power Applications, 2017.

[37] M. Markovic, M. Jufer, and Y. Perriard, "An exact formula for "tooth-totooth" permeance," IEEE Transactions on Magnetics, vol. 41, pp. 22952299, July 2005.

[38] E. Purcell, Electricity and Magnetism, third edition. Cambridge, 2008.
[39] R. P. Feynman, R. B. Leighton, and M. Sands, The Feynman Lectures on Physics, Volume II. Basic Books, 2010.

[40] J. R. Anglada and S. M. Sharkh, "Analytical calculation of air-gap magnetic field distribution in transverse-flux machines," in 2016 IEEE 25th International Symposium on Industrial Electronics (ISIE), pp. 141146, June 2016.

[41] J. R. Hendershot and T. J. E. Miller, Design of Brushless PermanentMagnet Machines. Motor Design Books LLC, 2010.

[42] T. Zickler, "Basic design and engineering of normal-conducting, irondominated electromagnets," in Proceedings of the CAS-CERN Accelerator School: Magnets, Bruges, Belgium, edited by D. Brandt, CERN2010-004, pp. 65-101, June 2009.

[43] S. Russenschuck, Field Computation for Accelerator Magnets. WileyVCH Verlag GmbH \& Co. KGaA, 2010.

[44] D. Tommasini, "Practical definitions and formulae for normal conducting magnets," tech. rep., CERN, Geneva, Switzerland, 2011.

[45] M. G. Say, The Performance and Design of Alternating Current Machines. Sir Isaac Pitman \& Sons Ltd., 1965.

[46] M. Mueller and H. Polinder, Electrical Drives for Direct Drive Renewable Energy Systems, 1st Edition. Woodhead Publishing., 2013.

[47] K. Y. Lu, E. Ritchie, P. O. Rasmussem, and P. Sandholdt, "Modeling and power factor analysis of a single phase surface mounted permanent magnet transverse flux machine," in Power Electronics and Drive Systems, 2003. PEDS 2003. The Fifth International Conference on, vol. 2, pp. 1609-1613 Vol.2, Nov 2003.

[48] K. Lu, P. O. Rasmussen, and E. Ritchie, "Design considerations of permanent magnet transverse flux machines," IEEE Transactions on Magnetics, vol. 47, pp. 2804-2807, Oct 2011.

[49] M. F. J. Kremers, J. J. H. Paulides, J. L. G. Janssen, and E. A. Lomonova, "Analytical flux linkage and emf calculation of a transverse flux machine," in Electrical Machines (ICEM), 2014 International Conference on, pp. 2668-2673, Sept 2014.

[50] M. F. J. Kremers, J. J. H. Paulides, and E. A. Lomonova, "Toward accurate design of a transverse flux machine using an analytical 3d magnetic charge model," IEEE Transactions on Magnetics, vol. 51, pp. 1-4, Nov 2015.

[51] P. Kundur, Power System Stability and Control. McGraw-Hill Professional, 1993.

[52] A. E. Fitzgerald, C. J. Kingsley, and S. D. Umans, Electric Machinery, Sixth Edition. McGraw-Hill Education, 2003.

[53] L. W. Matsch, Electromagnetic and Electromechanical Machines. Intext Educational Publishers, 1972.

\section{BIOGRAPHIES}

Jaime Renedo Anglada was born in Madrid, Spain in 1989. He received the M.Sc. degree in electro-mechanical engineering from the Comillas Pontifical University, Madrid, Spain, in 2013. He is currently pursuing the Ph.D. degree with the Mechatronics Research Group at the University of Southampton, UK. His research topic is the study of electric machines and drives for renewable energy applications.

Since March of 2017 he is with the Magnets, Superconductors and Cryostats (MSC) group of the Technology Department at the European Organization for Nuclear Research (CERN). He works in the design, construction, commissioning, maintenance and upgrade of the normal conducting magnets for present and future CERN accelerators and beam lines.

Suleiman M. Sharkh received the B.Eng. and Ph.D. degrees in electrical engineering from the University of Southampton, Southampton, U.K., in 1990 and 1994, respectively.

He is Professor of Power Electronics, Machines and Drives, and head of the Mechatronics Research Group at the University of Southampton. He is also the Managing Director of HiT Systems Ltd. He has published over 150 papers in academic journals and conferences. His main research interests are in the area of control, electrical machine and power electronics with applications to electric vehicles, marine propulsion, exhaust energy recovery and submersible pumps.

Prof. Sharkh is a senior member of the IEEE, a member of the IET and a Chartered Engineer. He was the 2008 winner of The Engineer Energy Innovation Award for his work on rim driven thrusters and marine turbine generators. 